\title{
A TEORIA DOS BENS COMUNS E A TEORIA DA EMANCIPAÇÃO COMO INSTRUMENTO DE CONSTRUÇÃO DE UM ESTADO DEMOCRÁTICO SOCIOAMBIENTAL E A RESPONSABILIDADE JURÍDICA NA ESPANHA E BRASIL
}

Elcio Nacur Rezende

Mestre e Doutor em Direito. Coordenador e Professor do Programa de Pós-graduação em Direito da Escola Superior Dom Helder Câmara.

Franclim Jorge Sobral de Brito Doutorando e Mestre em Direito. Coordenador e Professor da Graduação da Escola Superior Dom Helder Câmara.

\section{Resumo}

O presente trabalho dedica-se, eminentemente, a apresentar ao leitor a Teoria dos Bens Comuns e a Teoria da Emancipação. A primeira teoria, superficialmente, apresenta uma reflexão de quais são os limites para que o Estado, ou outro ente hiperssuficiente, explore os bens difusos em prol de um suposto interesse da sociedade. Náo obstante, a Teoria da Emancipação, também de forma perfunctória, analisa a possibilidade da superação da alienaçáo ideológica apresentando um mote desenvolvimentista fundado na autoconsciência do ser humano emancipado. Assim, ambas as teorias possuem pontos congruentes e dissonantes, mormente no chamado Socioambientalismo, na medida em que os bens ambientais, de importância incontestável, podem e devem ser geridos pelo Estado, sem, contudo, se olvidar da responsabilidade do cidadão nos cuidados em prol da preservação de um meio ambiente ecologicamente equilibrado.

\section{Palavras-chave}

Teoria dos Bens Comuns; Teoria da Emancipação; Socioambientalismo.

\section{Resumen}

Este trabajo está dedicado eminentemente introducir al lector a la teoría de los bienes comunes y la Teoría de la Emancipación. La primera teoría presenta superficialmente un reflejo de lo que los límites para el Estado, u otra hiperssuficiente entidad, exploran 
los bienes difusas en nombre de un supuesto interés de la sociedad. Sin embargo, la teoría de la emancipación, también forma superficial, explorar la posibilidad de superar la alienación ideológica que presenta un tema de desarrollo basado en la autoconciencia del ser humano emancipado. De este modo, ambas teorías tienen puntos congruentes y disonantes, especialmente en el llamado Socio-ambientalismo, en la medida en que los bienes ambientales, innegable importancia, pueden y deben ser manejados por el Estado, sin embargo olvidar la responsabilidad del ciudadano en el cuidado por el bien de preservación de un medio ambiente ecológicamente equilibrado.

\section{Palabras clave}

Teoría de los bienes comunes; Teoría de la Emancipación; Socio-ambientalismo.

\section{Introdução}

Neste limiar de século o ambientalismo está posto como desafio aos saberes científicos, legitimamente constituídos; e mais, vindica uma nova racionalidade para a compreensão deste fenômeno insurgente que se apresenta como resquício da ordem estabelecida dos séculos precedentes: as construçôes epistemológicas arregimentadas sob a égide cartesiana moderna. A saber, várias das manifestaçōes jurídicas e políticas remanescentes, tais como, Direitos Humanos, Dignidade da Pessoa Humana, Princípio do Mínimo Existencial, dentre outros, postulam hoje uma hermenêutica ambiental.

Nesse diapasão, Ambiente e Sociedade urgem conciliação na medida em que necessita-se de uma nova compreensão de conceitos como progresso, desenvolvimento, dignidade, além da tríade revolucionária: liberdade, igualdade e fraternidade, tendendo cada vez mais ao constitucionalismo ocidental, de forte acento liberal atentar para o Princípio Constitucional do Meio Ambiente Ecologicamente equilibrado, consagrado no artigo 225 da Constituição da República Federativa do Brasil, na ânsia de contemplar a crescente judicialização do espectro político. Destarte, pululam movimentos de cunho popular, oriundos da sociedade civil, sistematicamente ordenados ou nâo, que buscam dialogar frente ao paradigma econômico mundial.

Aqui se buscará tratar de dois desses: a Teoria dos Bens Comuns, fundamentada por Ugo Mattei (MATTEI, 2013), que se refere ao movimento social que se originou na Itália, a partir de vários grupos sociais, com força de poder constituinte na medida em que coloca na pauta jurídica novos limites à propriedade privada; ou, limites à privatização de bens coletivos (no Brasil estão juridicializados como bens difusos); e a Teoria da Emancipação, de herança marxista, fundamentada a priori no ensaio Sobre a Questáo Judaica (MARX, 2010), que, em seguida, se desenvolveu no pensamento de Max Horkheimer, 
na sua obra Teoria Tradicional e Teoria Crítica (HORKHEIMER, 1975) e que se apresenta hoje no pensamento de Boaventura Souza Santos, na obra Renovar a Teoria Crítica e Reinventar a Emancipação Social (SANTOS, 2007) - estes são apenas fragmentos da genealogia emancipatória.

\section{Desenvolvimento}

A Teoria dos Bens Comuns e a Teoria da Emancipação dialogam de alguma maneira com o movimento ambientalista emergente, sobretudo no que se chama de socioambientalismo: fusão dos paradigmas econômico, social e ambiental. Será no horizonte crítico à estatização dos bens comuns sob o argumento de que o homem médio não é capaz de gerir seu ethos social, dada sua condição não emancipada, que se analisará estes institutos de manifestação popular para se considerar a possibilidade de uma nova racionalidade pluralista que seja capaz de inverter a lógica da regulamentação global para atender demandas locais.

O discurso hegemônico disseminado na lógica política e jurídica está ameaçado pela força de corporaçóes globais que encampam matrizes de governabilidade pautadas na eficiência e no progresso para subverter a concepção política patrimonialista. Assim, empresas multinacionais se apropriam de bens comuns (ou públicos, de todos) com a preleção gerencial de regular a economia mundial sob o pretexto de que se deve produzir bens de consumo em larga escala para que mais pessoas satisfaçam sua ânsia por cidadania.

Esta noção reducionista imperialista colide com limites impostos pela natureza, em primeiro lugar, e por pessoas das mais diversas realidades que vindicam sua autoafirmação no espaço público. Junto a frenesi da multidão que associa, por um lado, cidadania, acesso, bem-estar à possibilidade de participação da lógica especulativa do risco econômico, de outro buscam denunciar este modelo nocivo que está comprometendo a natureza e a sua própria espécie.

Correlato a estas premissas introdutórias, devemos tratar, como dito acima, dos dois caminhos possíveis de denúncia: Teoria dos Bens Comuns e Teoria da Emancipação - o primeiro assentando na dicotomia patrimonialista e o segundo na impossibilidade de fruição da condição humana e política na sua excelência.

A Teoria dos Bens Comuns busca superar a antinomia que se apresenta entre a propriedade pública e a propriedade privada. Esta surge da indagação: pode o gestor público, governo, liquidar os bens públicos, da coletividade? Qual o preço da água? Ou, antes, a quem pertence a água? São questóes que desafiam a ordem política na medida em que as privatizaçóes expropriam a coletividade e invertem a noção de bem comum, haja vista que bem comum não pode ser cotizado monetariamente para fins de gestão eficiente de governabilidade, tão pouco exercer a função de equilíbrio econômico. 
Tratamos, pois, de uma teoria que concatena analiticamente quatro acepçóes:

“a) a estrutura do sistema de recursos comuns; b) os atributos e o comportamento do grupo de usuários; c) as regras de acesso e uso que os usuários utilizam para manejar o recurso comum; e d) os resultados obtidos pela adoção dessas regras e pelo comportamento dos usuários”. (OSTROM, 1990 apud CUNHA, 2004, p. 19):

A tradição liberal constitucional guarnece ao proprietário privado instrumentos jurídicos de garantia ao seu patrimônio, porém não protege a coletividade da ação expropriadora do Estado que transfere para a propriedade privada aqueles da coletividade. Assim, Ugo Mattei, sugere por meio do Movimento Social dos Bens Comuns, um limite a estas transaçóes:

The Italian beni comuni movement is not only a powerful example of the way in which social movements are emerging as an important form of constituent power at the level of the nation-state, but also at the supranational level to limit of transnational actors in the absence of a transnational form of representative government. (MATTEI, p. 968).

Esta dupla limitação sugerida acima, com relação ao Estado e à ordem global, internacional, são exemplos de como o avanço corporativo deve ser limitado sob pena de privação dos bens comuns. Por exemplo, empresas multinacionais compram nascentes de água para que possam lucrar na sua escassez com o argumento de que estão a fazer um bem social de proteçáo coletiva quando, em verdade, buscam egoisticamente o lucro e olvidam de qualquer zelo com a Teoria da Solidariedade Intergeracional que, como se sabe, sustenta-se, perfunctoriamente, na preocupação incessante da preservação de um meio ambiente ecologicamente equilibrado para as geraçóes vindouras, tratando, assim, os bens ambientais náo como fonte inesgotável de riqueza e sim, acertadamente, como uma riqueza que pertence à humanidade. Nesse sentido

A preservação do meio ambiente está obrigatoriamente focalizada no futuro. Uma decisão consciente para evitar o esgotamento dos recursos naturais globais, em vez de nos beneficiarmos ao máximo das possibilidades que nos sãos dadas hoje, envolve necessariamente pensar sobre o futuro. Entretanto o futuro pode ter uma dimensão de médio ou longo prazo, enquanto a preocupação relacionada ao interesse das geraçôes futuras é, necessariamente, de longo prazo e, sem dúvida, um compromisso vago. (...) A mudança global que está ocorrendo no momento afeta não só os recursos naturais, mas também os recursos culturais humanos que foram acumulados durante milhares de anos. Esses recursos consistem, por exemplo, de conhecimentos de povos indígenas, de registros científicos ou até mesmo de películas que se deterioraram com o passar do tempo. Fatores psicológicos e éticos explicam nossas reaçôes a tais questóes. Nossa 
primeira reação pode ser genética, instintiva. Todas as espécies vivas procuram instintivamente assegurar sua reprodução, e os mais desenvolvidos entre elas também fazem a provisão para o futuro bem-estar de seus descendentes. A história humana é testemunha dos constantes esforços dos seres humanos para proteger não somente suas próprias vidas, mas também para garantir o bem-estar e melhorar as oportunidades para sua prole. Os cuidados instintivos com as crianças e netos fazem parte da natureza humana. (KISS, 2004):

A tradição ocidental moderna se assentou na dupla relação entre Estado-propriedade privada, resguardando a noção liberal de John Lock de que é necessário proteger o particular diante do Estado. Porém, a proposta de Mattei é dar o passo à compreensão inversa, do Estado perante a coletividade (titular dos bens comuns). Para tanto, vindica uma nova moldura constitucional capaz de cumprir com a função de proteção dos bens públicos frente ao Estado neoliberal e ao poder privado das grandes corporaçôes globais.

Nessa esteira, a proteçáo aos bens comuns surge da luta pela garantia do espaço coletivo como lugar de fruição da cidadania, administrado pelo governo. Neste ponto, tal teoria se aproxima da agenda ambiental na medida em que busca romper com o complexo modelo industrial que avança sobre a natureza com o objetivo de dominá-la, transformá -la e dispô-la como produto.

A Teoria dos Bens Comuns alcançou seu ápice quando, em 2009, Elinor Ostrom os tratou como comuns, na obra A governança dos comuns, recebendo o Nobel da economia. Porém, seu potencial crítico ficou ameaçado por resistências à posição central dos comuns entre as categorias do político e do jurídico. Surge daí uma nova controvérsia, chamada de a tragédia dos comuns, uma vez que se constatou o inverso da teoria dos bens comuns, quando a multidão superexploram tais bens levando-os à exaustão. Isto é, se antes o perigo estava na privatização do bem agora se situa na apropriação deliberada pela coletividade, seus titulares.

Assim, os intelectuais preferiram um caminho alternativo, de tratar os bens comuns como lugar do não direito. Utilizaram a imagem de "uma pessoa convidada para um banquete que se alimenta muito mais de que precisa para acumular calorias à custa dos outros", no entanto essa imagem carece de correspondência com o real; pois só se pode constatar esse cenário numa sociedade não emancipada. Ora, o contrário também é previsível, e com efeitos muito mais drásticos: quando uma empresa multinacional compra todas as nascentes de água que perfazem seu capital sob a chancela da concessão do Estado; buscam possuir o máximo de recursos à custa da coletividade.

Leciona Rodotá:

La evidencia empírica muestra un derecho y una política convertidos en instrumentos de gestión de lo cotidiano, con la transformación del 
derecho en mandato ocasional y de la política en administración. (2010, p. 29)

Nesse diapasáo, a teoria dos bens comuns corre o risco de ser absorvida por discursos jurídicos e ambientais pouco eficientes, quando geridos por corporaçóes que objetivam lucros, como, por exemplo, não direito ou sustentabilidade. $\mathrm{O}$ primeiro denuncia que direito e política deveriam se unir em um projeto comum de bom governo, com gestáo eficiente dos recursos naturais e limites à gestão estatal dos bens coletivos, dentre outros; o segundo, embora seja um conceito da década de 80, cunhado no Relatório de Brundtland, tem sido frequentemente assumido como possibilidade de se agregar valor às marcas globais por meio de eficiente mecanismo de marketing.

Justamente nesse ponto surge o tão comentado Princípio do Desenvolvimento Sustentável que busca, em assertiva superficial, a busca pelo crescimento econômico sem, contudo, olvidar-se da preservação ambiental:

"O principal desafio deste século - para os cientistas sociais, os cientistas da natureza e todas as pessoas - será a construçấo de comunidades ecologicamente sustentáveis, organizadas de tal modo que suas tecnologias e instituiçõos sociais - suas estruturas materiais e sociais - não prejudiquem a capacidade intrínseca da natureza de sustentar a vida" (CAPRA, 2005, 17).

Soma-se a essas indagaçóes o modelo constitucional que está disposto potestativamente; o conceito de soberania popular que desafia a lógica liberal; e a força hegemônica contra o constitucionalismo econômico, por meio do combate às privatizaçóes. É preciso fazer ecoar os direitos fundamentais da coletividade tal qual é indispensável repensar a razão moderna que abriu o cofre dos recursos naturais, pós-revolução industrial, dissipando os bens comuns. $\mathrm{O}$ modelo de ciência que opera a extração e a expropriação desses recursos para fins comerciais se associou a uma visão equivocada de progresso.

No entanto, este modelo fundamentado no discurso iluminista teve como grande inspiração a possibilidade de o homem romper com o mito medieval - religioso - e ser capaz de gerir autonomamente sua condição vital de existência, conhecendo por sua própria inteligência e tendo como fruto a ação discernida desse saber. Alguns séculos depois se percebe que o homem continua envolvido pelo mito de que existe fora de si. Nessa perspectiva se buscará tratar da emancipação como instância dessa limitação e como desdobramento da teoria dos bens comuns - uma vez que este postula vocabulário emancipatório.

A Emancipação, conforme já mencionado acima, está fundamentada em Karl Marx e articulada como princípio universal da Teoria Crítica, sistematizada por Max Horkheimer, e posteriormente Boaventura Souza Santos e outros teóricos críticos. Sua intenção é 
romper com a alienação ideológica e sugerir um novo modelo de razão desenvolvimentista, centrada na autoconsciência do sujeito, isto é, do homem emancipado. Nesse sentido,

A finalidade da teoria crítica é definida pelo seu princípio básico - a possibilidade da emancipação. O conhecimento é o meio para se realizar um projeto de fronteiras com proporções muito mais largas, muito mais profundas. Aliás, nenhum elemento isolado, sob o ponto de vista da teoria crítica, torna-se suficiente para compreensão social. O que é central na compreensão da sociedade é sempre resultado da relação de suas várias dimensões, portanto, é o todo social. Horkheimer ultrapassa a questão do conhecimento em si e expande sua análise às condições históricas nas quais se gera o conhecimento. Neste caso, seria mais preciso afirmar que a teoria crítica analisa as condiçôes em que ao conhecimento impóem-se limitaçóes a fim de dar forma a um tipo determinado de conhecimento com ênfase no status de cientificidade. O curioso é que justamente os elementos reivindicados para garantirem a cientificidade são, do ponto de vista crítico, aqueles que afastam a possibilidade de se tornar um conhecimento, de fato, científico, quais sejam, a neutralidade do sujeito em relação ao objeto, a objetivação absoluta do objeto, o isolamento do objeto em relação à realidade na qual deveria permanecer inserido (SILVA REIS, 2013).

Para tanto, é preciso delinear a emancipação enquanto luta em desfavor às relaçóes de opressão e alienação, e fim à relaçáo manipuladora do homem com a natureza, a partir da desnaturalização crítica dos processos sociais. Como se iniciou este texto sugerindo uma reconciliação entre sociedade e natureza, o viés emancipatório que se utilizará será na perspectiva socioambiental emergido de uma visão de totalidade do ambiente em estrita relação ao social.

Ademais, a Emancipação Socioambiental indica uma confluência dos espaços público e privado resignificando o modelo clássico de liberdade para outro justificado na irrupção do social, que traz uma fusão indistinta das duas realidades tão bem delineadas na antiguidade, conforme afirma Hannah Arendt (2011): "o social é a fusão do público e do privado".

Têm-se ainda outras perspectivas emancipatórias que não serão objeto deste texto (a jurídica, por exemplo) por não corroborar com a hipótese delimitada: de uma nova racionalidade crítica à estatização dos bens comuns sob o argumento de que o homem médio não é capaz de gerir seu ethos social, dada sua condição não emancipada. Assim, a Emancipação Socioambiental indica alguns caminhos possíveis; aqui será abordado dois: o primeiro de uma ruptura da estatização das relaçóes sociais e humanas; e a segunda, derivada da primeira, da pontencialidade do sujeito autoconsciente.

A centralidade do Estado moderno se estabeleceu em três pilares fundamentais: jurídico, político e econômico. Desde a Revolução Francesa, que suscitou uma nova forma 
constitucional capaz de agregar esta tríade sob o baluarte da liberdade experimenta-se consequências nefastas para o que hoje o próprio ente estatal apregoa aos seus cidadáos - o homem criou o Estado e este o submeteu -. Todas as manifestaçóes emancipatórias deste modelo - por exemplo, Direitos Humanos, de alguma maneira fracassaram em virtude de enredar sujeito e objeto no mesmo horizonte ideológico. Assim,

É bem verdade que essa "liberdade" não nasce, no entreabrir da Modernidade, como uma conquista produzida por uma iniciativa única, tampouco universal. Demandaria em sequência a luta pela aboliçâo do tráfico, da mercantilização e da escravidão de estrangeiros, em especial do africano. O paradigma do cidadáo - homem livre - apto ao exercício da autonomia da vontade constitui, entretanto, uma das precondiçóes para que a Revoluçáo Industrial se desenvolva por meio do trabalho juridicamente livre e ajustado mediante consentimento. $\mathrm{O}$ itinerário será robustecido, na França, pelo advento da Lei Le Chapelier (1791), que pôs termo às corporaçóes de ofício medievais, às coligações empresariais e também de trabalhadores. Esse diploma indica que o trabalhador juridicamente "livre", enaltecido pelo ideário liberal da Revolução Francesa, é por excelência o indivíduo (FREITAS JR., 2014).

E por este sistema não favorecer a emancipação, cada vez mais pessoas se tornam dependentes da gestão pública como forma de subsistência, que, por sua vez, sofisticou-se e alcançou o patamar biopolítico, em que a própria vida humana se tornou seu principal algoz de manipulação e interesse político. Nessa esteira, o jurídico se transformou em instrumento indispensável ao modelo de civilização pautada na prestação de serviços, de cunho assistencialista, e gestáo eficiente de contençáo e equilíbrio econômico.

Levantar a voz a não estatização pode parecer anacrônico se a governabilidade assume a condição primordial de administrador burocrático da res pública e privada, pois ambas não estão dissociadas. Porém, o que advoga a teoria dos bens comuns e sua potencialidade emancipatória é justamente a compreensão acertada do que se pode chamar de contenção estatal: não em relação ao Estado perante o indivíduo, mas, ao contrário, do indivíduo perante o Estado. Uma mostra recente disso foi a Rio+20 (Conferência das Naçôes Unidas para o Meio Ambiente e o Desenvolvimento Sustentável) que aconteceu alijada da Cúpula dos Povos (Movimento paralelo à Conferência oficial, conhecida como Contra-Conferência) em que a produçáo de conhecimentos locais, a partir de realidades concretas não foi sequer ouvida para a confecçáo do documento O futuro que queremos.

O futuro que se quer é de um sujeito emancipado? Mas emancipado de quê e de quem? Sem dúvida da dominação estatal, porém, com maior acento, da dominação econômica neoliberal das grandes corporaçóes multinacionais que estão submetendo o Estado ao risco global especulativo dos índices econômicos, que representam a insolvência do 
projeto moderno político e jurídico. Lógica que promove o descontrole estatal em relação aos interesses comuns por limitar a ação de seus cidadáos.

Em segundo lugar, e na continuidade da desestatização, surge outro elemento fundamental que é a autoconsciência do sujeito, e que exige uma hermenêutica nova para abordar a relação sujeito-objeto; se o objeto conduz o sujeito à sua consciência, é preciso inverter esse processo: o sujeito conduzir o objeto à sua consciência. Isto é, fazer cumprir o principal argumento da modernidade, e sob o qual todos estão articulados: fazer o homem conhecer pela sua própria inteligência e, assim, discernir sua opção.

A emancipação posta dessa maneira significa um enorme desafio ao que se pode compreender atualmente por mercado, em que maiorias dos processos econômicos do ocidente estão articulados como forma de promoção da indução ao estilo de vida capaz de satisfazer as condições necessárias de uma sociedade justa. Já não cabe ao individuo escolher entre duas possibilidades antagônicas, mas entre duas possibilidades que coincidem na sua expectativa, de geraçáo de lucros e transferência de riquezas. A respeito do chamado consumismo ressaltamos:

Pode-se dizer que o "consumismo" é um tipo de arranjo social resultante da reciclagem de vontades, desejos e anseios humanos rotineiros, permanentes e, por assim dizer, "neutros quanto ao regime", transformando-os na principal força propulsora e operativa da sociedade, uma força que coordena a reprodução sistêmica, a integração e estratificação sociais, além da formação de indivíduos humanos, desempenhando ao mesmo tempo um papel importante nos processos de auto-identificação individual e de grupo, assim como na seleção e execução de políticas de vida individuais. O "consumismo" chega quando o consumo assume o papel-chave que na sociedade de produtores era exercido pelo trabalho. Como insiste Mary Douglas, "a menos que saibamos porque as pessoas precisam de bens de luxo [ou seja, bens que excedem as necessidades de sobrevivência] e como os utilizam, náo estaremos nem perto de considerar com seriedade os problemas da desigualdade (BAUMAN, 2008, p. 41).

Assim, várias das manifestaçóes contrárias a esse monstro social tem sido denunciadas, mas muitas também tem sido cooptadas, inclusive o discurso ambiental: optar pela sustentabilidade, por formas de vida condizentes à natureza do Cosmos, tem se demonstrado pela opção verde que empresas agregam às suas marcas, aos seus rótulos. Pouco se sabe o que faz esta ou aquela empresa, se apenas o mínimo de sua produção atende às especificaçóes que autorizam o slogan verde, porém utilizar o objeto (meio) verde faz com que a opção do sujeito seja conscientemente satisfeita.

Autoconsciência vai além dessa tendência mercadológica, busca um conhecimento ético, pautado em modo de vida que expresse a dimensão socioambientalista como forma 
de manifestação consciente no uso dos bens comuns, na opção atrativa do objeto livre do condicionamento imposto.

O vocabulário da emancipação, sobretudo este de inclinação socioambiental, coincide com os pressupostos da teoria dos bens comuns. Ou seja, o que se postula em comuns é justamente a luta emancipatória de reconhecimento da coletividade como titular de um direito que está sobrestado pela representação governamental que não reconhece entre seus cidadãos a capacidade de gestão destes bens. A responsabilidade pela construção de um Estado Socioambiental deve perpassar pelos princípios norteadores da Democracia que, justamente, possui como premissa a homenagem máxima ao interesse da sociedade, ainda que, lamentavelmente, colidam com a gestão da res publica. Nesse sentido:

A dúvida se torna um círculo vicioso. Com a arte de negociar interesses comuns e destinos compartilhados caída em desuso [...] e com a ideia de "bem comum" [...] sendo marcada com as marcas da suspeita, da ameaça, da nebulosidade e da tolice, a busca por segurança em uma identidade comum - ao invés de em um acordo de interesses comuns - emerge como a mais sensata, efetiva e produtiva maneira de proceder; porém, as preocupações com a identidade e suas defesas contra a poluição fazem da ideia de interesses comuns [...] a mais incrível de todas e também a mais fantástica, sendo a habilidade e a vontade para persegui-las as características menos prováveis de aparecerem. (BAUMAN apud SANTOS, 2012)

Se emancipação está fundamentalmente remetida à condição de fruição humana e política do espaço público, de forma corresponsavelmente ética, entre iguais (entendese coletividade), a teoria dos bens comuns corrobora de maneira imprescindível a esta compreensão sistêmica de organização popular. Ademais, esta se mostra como elementar à noção de reconciliação entre sociedade e natureza, uma vez que a titularidade social do bem natural é relacional, em que limites jurídicos são interpostos, utopicamente, como contingência ao exercício não da cidadania, mas das empresas multinacionais que expropriam o ambiente e alienam o cidadão.

Quando tratamos de Direito Ambiental e Desenvolvimento Sustentável, o papel do Estado e do Cidadão na construção de uma sociedade que respeita preceitos constitucionais torna-se pujante, pois, parte-se do princípio fundamental da Solidariedade, onde todos são responsáveis (Estado e Ser Humano) por atitudes que busquem preservar o meio ambiente sem, contudo, olvidarem da busca pelo desenvolvimento econômico.

Com efeito, dispõe a Constituição da República Federativa do Brasil:

Art. 225. Todos têm direito ao meio ambiente ecologicamente equilibrado, bem de uso comum do povo e essencial à sadia qualidade de vida, impondo-se ao Poder Público e à coletividade o dever de defendê-lo e preservá- lo para as presentes e futuras geraçôes. 
$\$ 3^{\circ}$ As condutas e atividades consideradas lesivas ao meio ambiente sujeitarão os infratores, pessoas físicas ou jurídicas, a sanções penais e administrativas, independentemente da obrigação de reparar os danos causados.

A Constituição espanhola dispóe em seu artigo 45:

Art 45.1 Todos tienen el derecho a disfrutar de un medio ambiente adecuado para el desarrollo de la persona, así como el deber de conservarlo.

45.2. Los poderes públicos velarán por la utilización racional de todos los recursos naturales con el fin de proteger y mejorar la caliad de la vida y defender y restaurar el medio ambiente, apoyándose en la indispensable soliaridad colectiva.

45.3. Para quienes violen lo dispuesto en el apartado anterior, en los términos que la ley fije, se establecerán sanciones penales o, en su caso, administrativas, así como la obligación de reparar el daño causado.

Ressalte-se, ainda que na Espanha foi publicada em 2007 a Lei 26 que trata exclusivamente da Responsabilidade por Danos ao Meio Ambiente, dispondo no primeiro parágrafo do seu preâmbulo, assinado pelo Rei Juan Carlos I:

El artículo 45 de la Constitución reconoce el derecho de los ciudadanos a disfrutar de un medio ambiente adecuado como condición indispensable para el desarrollo de la persona, al tiempo que establece que quienes incumplan la obligación de utilizar racionalmente los recursos naturales y la de conservar la naturaleza estarán obligados a reparar el daño causado con independencia de las sanciones administrativas o penales que también correspondan.

Analisando os textos das Constituições brasileira e espanhola conclui-se que todos, Estado de cidadãos, tem o dever de preservar o meio ambiente.

Ora, analisando a Teoria dos Bens Comuns e a Teoria da Emancipação a partir dos preceitos constitucionais colacionados, conclui-se, inexoravelmente, que em verdade, ainda que a afirmação seja utópica, o papel do Estado e do cidadão devem se conciliar, pois o interesse deveria convergir na busca da preservação ambiental intergeracional, bem como, na indiscutível necessidade da maximização do desenvolvimento econômico.

Em homenagem ao disposto, surge na Diretiva 2004/35, que em seu artigo 7º, 1, impóe que se identifique "potenciais medidas de reparação e apresenta-las à autoridade competente, para aprovaçáo (...)." Assim, nesse caso, "decidir das medidas de reparação a 
aplicar, nos termos do Anexo II, se necessário, com a cooperação de operador em causa." (UNIÃO EUROPEIA, 2004) ${ }^{1}$

Ao tomar essa decisão, a autoridade competente deve atender, nomeadamente, à natureza, à extensão e à gravidade das diversas situaçôes de dano ambiental em causa, bem como às possibilidades de regeneração natural. Os riscos para a saúde humana também devem ser tomados em consideração." (UNIÃO EUROPEIA, 2004)²

Importa também destacar que

Em relação aos danos ambientais, a presente directiva (sic) deve aplicar-se a atividades (sic) ocupacionais que apresentem riscos para a saúde humana ou o ambiente. Essas atividades (sic) devem, em princípio, ser identificadas por referência à legislação comunitária pertinente que prevê requisitos regulamentares em relaçâo a certas atividades $($ sic) ou práticas consideradas como suscitando um risco potencial ou real para a saúde humana ou o ambiente." (UNIÂO EUROPEIA, 2004) ${ }^{3}$

Nesse caso, como já dissemos, resta à humanidade construir uma teoria de responsabilidade ambiental, mudando de paradigma no tocante à aplicaçáo do princípio de poluidor-pagador, para uma ética do humano, nos dizeres de Boff, abarcada na solidariedade planetária, evitando-se, pata tanto a irresponsabilidade degradadora do ser humano racional e irracional pela depredaçáo do meio ambiente, uma vez que preservar os recursos naturais para as geraçôes vindouras, não é apenas uma questão de sustentabilidade, mas também uma questão de justiça e de equidade, bem como uma imperatividade ético-moral, pois saber cuidar é um comando que deve nortear o ser humano em seu agir comportamental para com o meio ambiente ecologicamente equilibrado.

Portanto, a articulaçáo crítica dessas duas perspectivas abordadas, e complementares, vindicam a grafia do sujeito como protagonista de sua história existencial e política, por isso este breve ensaio provoca a uma leitura ampliada da autonomia autoconsciente, em que cada um e todos são autores de sua escrita: Sei que Deus mora em mim como sua melhor casa, sou sua paisagem, sua retorta alquímica, e para sua alegria, seus dois olhos, mas esta letra é minha. (Adélia Prado, 2009)

\section{Conclusões}

A Teoria dos Bens Comuns analisa as divergências filosóficas, jurídicas e políticas entre a propriedade privada e o bem público, tendo por principal escopo a superação de

\footnotetext{
1 Cf. Diretiva 2004/35, art. $7^{\circ}, 1$.

2 Cf. Diretiva $2004 / 35$, art. $7^{\circ}, 3$

3 Cf. Diretiva 2004/35, Preâmbulo, (8).
} 
entendimentos que apresentam uma inviabilidade de existência pacífica desses domínios. Com isso, busca ressaltar que, em verdade, o que deve conduzir a lógica jurídica e a administração pública nos seus atos de gestão é o interesse de todos, de forma paritária.

A Teoria da Emancipação, fundamentada em Karl Marx e sistematizada por Max Horkheimer, tem por objetivo apresentar um contra-modelo - que na linguagem de Boaventura Souza Santos é contra-hegemônico - desenvolvimentista, baseado na autoconsciência do indivíduo, sustentando, pois, que uma vez constatado que o homem detém certo esclarecimento, este deve se conduzir com liberdade.

Portanto, ambas as teorias se inserem na tradição da Teoria Crítica a partir de seu princípio de orientação à emancipação, que descende do pensamento marxista, e se articula à nova hermenêutica ambiental contemporânea. A degradação do ambiente está relacionada ao modelo político-jurídico liberal que sustenta, em distintas Cartas Constitucionais, o progresso como utopia legítima para subtrair a relação original homem-natureza.

Dessa forma, pode-se apontar a Emancipação com viés Socioambiental, que perpassa pela análise da Teoria dos Bens Comuns e dos teóricos acima apontados, uma vez que busca articular o social e o ambiental a partir de uma visão holística da sociedade, com potencial de agregar a fundamentação filosófica e, por conseguinte, jurídica, na medida em que a Ciência do Direito tem por papel, dentre outras, a análise da organização do Estado.

Não obstante, constatada a importância da construção de um modelo de Estado pautado pela Emancipação - em contrapartida ao de Regulação -, demonstramos a consequência jurídica do desrespeito à preservação ambiental, quer pelos cidadãos, quer pela gestão pública, no que tange ao ambiente, bem tutelado pelas constituiçóes espanhola e brasileira, bem como, por todos minimamente conscientes de sua responsabilidade perante a preservação para a atual e futuras geraçóes de um ambiente ecologicamente equilibrado.

\section{Referências}

ARENDT, Hannah. A Condiçáo Humana. Tradução de Roberto Raposo. Rio de Janeiro: Forense Universitária, 2010.

BAUMAN, Zygmunt. Vida para Consumo: a transformação das pessoas em mercadoria. Tradução Carlos Alberto Medeiros - Rio de Janeiro: Zahar, 2008.

BOBBIO, Norberto. A era dos direitos. Tradução de Carlos Nelson Coutinho. Rio de Janeiro: Elsevier, 2004.

BOFF, Leonardo. Saber cuidar: ética do humano - compaixão pela terra. Petrópolis: Vozes, 1999. 
CAPRA, Fritjof. As Conexóes Ocultas: Ciência para uma vida sustentável. CIPOLLA, Marcelo Brandão, tradução. São Paulo: Cultrex, 2005.

FREITAS JR., Antônio Rodrigues. O trabalho à procura de um direito: crise econômica, conflitos de classe e proteçáo social na Modernidade. Disponível em <http:// www.scielo.br/scielo.php?pid=S0103-40142014000200006\&script=sci_arttext $>$ Acesso em: 11 maio 2015.

HORKHEIMER, Max. Teoria Tradicional e Teoria Crítica. São Paulo: Abril Cultural. (Col. Os Pensadores, vol XLVIII), 1975.

KISS, Alexandre. Os Direitos e interesses das geraçóes futuras e o princípio da precaução. In: VARELLA, Marcelo Dias; PLATIAU, Ana Flávia Barros (Organizadores e Co-autores). Princípio da Precauçáo. Belo Horizonte: Del Rey e ESMPU - Escola Superior do Ministério Público da União, 2004.

MARX, Karl. Sobre a questão Judaica. São Paulo: Boitempo, 2010.

MATTEI, Ugo; BAILEY, Saki. Social Movements as Consttuent Power: The Italian Struggle for the Comons. Indiana University Maurer School of Law. Indiana Journal of Global Legal Studies, v. 20, Issue 2, 2013.

MATTEI, Ugo. Por uma Constituição baseada nos bens comuns. Disponível em <http://www.diplomatique.org.br/artigo.php?id=1065>. Acesso em: 11 maio 2015.

MATTEI, Ugo. Uma breve genealogia dos “bens comuns”. Disponível em http://www. ihu.unisinos.br/noticias/44117-um-breve-genealogia-dos-bens-comuns. Acesso em: 11 maio 2015.

NOBRE, Marcos. Curso Livre de Teoria Crítica. 3a edição. Campinas: Papirus, 2013.

OSTROM, E. Governing the commons: the evolution of institutions for collective action. Cambridge: Cambridge University Press, 1990.

PRADO, Adélia. Direitos Humanos. In: Oráculos de Maio. São Paulo: Record, 2007, p. 73.

RODOTÀ, Stefano. La vida y las reglas. Entre el derecho y el no derecho. Traducción de Andrea Greppi. Madri: Editorial Trotta, 2010.

SANTOS, Boaventura de Souza. Renovar a Teoria Crítica e Reinventar a Emancipação Social. São Paulo: Boitempo, 2007.

SANTOS, Guilherme Ferreira. Análise do Discurso Crítica e Emancipação: contribuiçóes a partir da visão de Bauman. Disponível em <http://www.iel.unicamp.br/ sidis/anais/pdf/SANTOS_GUILHERME_FERREIRA.pdf> Acesso em: 11 maio 2015 . 
SILVA REIS, Francisco das Chagas. A Emancipação em Horkheimer e Adorno e a crítica de Habermas. Disponível em <http://www.ufpi.br/subsiteFiles/eticaepistemologia/arquivos/files/Disserta\%C3\%A7\%C3\%A3o\%20-\%20Francisco\%20das\%20 Chagas\%20-\%20Final.pdf> Acesso em 07/05/2015.

UNIÃO EUROPEIA. Directiva 2004/35 do Parlamento Europeu e do Conselho de 21 de abril de 2004, relativa à responsabilidade ambiental em termos de prevenção e Reparação de danos ambientais. Disponível em: <http://www.isp.pt/winlib/cgi/ winlib.exe? skey=\&pesq=2\&doc=14371> Acesso em: 11 maio 2015.

ZAGREBELSKY, Gustavo. El derecho dúctil. Tradução de Marina Gascón. Madrid: Trotta, 2007.

Especiais agradecimentos à FAPEMIG (Fundação de Amparo à Pesquisa do Estado de Minas Gerais) pelo apoio financeiro recebido pelo autor Elcio Nacur Rezende na participação deste evento na cidade de Madrid/Espanha. 